\title{
Implementing the Red, Green and Blue Education Project and Innovating the Training Mode of Compound Applied Talents in Printing \& Packaging
}

\author{
Yonggang Yang ${ }^{1, *}$, Tingyu Feng ${ }^{1}$ and Qiaozhuo $\mathrm{Gao}^{2}$ \\ ${ }^{1}$ School of Printing \& Packaging Engineering, Beijing Institute of Graphic Communication, Beijing, 102600, China \\ ${ }^{2}$ The Emerald City Branch of Beijing Primary School, Beijing, 102600, China \\ ${ }^{*}$ Corresponding author. Email: yangyonggang@bigc.edu.cn
}

\begin{abstract}
In order to cultivate compound application-oriented talents, the printing major of the school implemented the "Red, Green, and Blue" education project under the background of the "Excellent Engineer Education and Training Program" of the Ministry of Education. The "red" in the "red, green and blue" education project is to take the Chinese long-standing printing civilization and the inheritance of the red printing culture as its mission, "green" is guided by the development of green, intelligent printing and packaging technology in the new era, and "blue" is pioneering blue ocean, strengthening practice, continuous innovation, and training compound application-oriented talents. The article mainly introduces the background of the project, the main research content of the project and the training mode of printing and packaging applied talents. The implementation of the "Red, Green, and Blue" education project aims to adapt to the new development stage and innovate the training model of printing and packaging composite application-oriented talents.
\end{abstract} Keywords: printing engineering major, excellent engineer, talent training, compound application talents,

"Red, Green, and Blue" education project

\section{INTRODUCTION}

In order to implement the "Outline of the National Medium and Long-term Education Reform and Development Plan (2010-2020)" and the "Outline of the National Medium and Long-term Talent Development Plan (2010-2020)", the Ministry of Education launched the "Excellent Engineer Education" in June 2010[1]. The training plan" aims to cultivate a large number of high-quality engineering and technical personnel with strong innovation ability and meet the needs of economic and social development. Beijing Institute of Graphic Communication is the second batch of pilot units for the "Excellent Engineer Education and Training Program" of the Ministry of Education (printing engineering is one of the pilot majors). Beijing Institute of Graphic Communication is a university that participated in the launch of Beijing's "Excellent Engineer Education and Training Program" established in January 2012 alliance[2]. In November 2012, the school issued the "Implementation Plan for the Education and Training Plan for Outstanding Engineers". In December, the opening ceremony of the "Bisheng Excellent Class", a pilot class for the excellence plan, was held. In January 2018, in the "Publication of the Results of New Engineering Research and Practice Projects" published by the Ministry of Education, the "Belt and Road-oriented Printing Engineering Education Internationalization Research and Practice" declared by this achievement team was successfully approved. The pilot program of the Ministry of Education's outstanding engineer training program and the implementation of the new engineering research and practice project indicates that the training of composite application-oriented innovative talents for printing and packaging majors has entered a new stage of development.

\section{THE MAIN RESEARCH CONTENT OF THE PROJECT}

The "red, green and blue" in the results represent the three primary colors of color and light, which is one of the labels and characteristics of the printer. With this as the implication, the implementation of the "Red, Green and Blue Education Project" is to take the Chinese longstanding printing civilization and the inheritance of the red printing culture as its mission, and to guide the development of green, intelligent printing and packaging technology in the new era[3].The implementation of the project is based on the development of the blue ocean, strengthening of practice, and continuous innovation. The implementation of the project adheres to the establishment of morality and talent cultivation, and cultivates composite application-oriented talents with cultural and professional self-confidence, strong practical ability, and good industry development vision. 
This achievement focuses on implementing the "Red, Green, and Blue" education projects in phase, including the "Red Thought Leading Program", "Green Technology Awareness Program", and "Blue Innovation Promotion Program". The Red Plan is mainly carried out in the first year of the freshman year. Through courses and special activities such as Introduction to Printing, "Everyone Tells the Story of Red Printing", to strengthen the entrance professional education of "patriotism, love of school, love of profession" and self-confidence education of red printing culture; The green plan is mainly carried out in the second and third grades, implementing green scientific research and practical actions, and deepening the understanding of the green printing and packaging strategy theory and planning; The Blue Project is mainly carried out in the fourth grade[4]. Through practical training plans and school-enterprise linkages, it explores the development direction of industry and technology, and cultivates students' comprehensive ability by solving related technical problems. This achievement is based on the construction of a first-class national-level major in printing engineering and a provincial-level first-class major in packaging engineering, relying on the first batch of new engineering research and practice projects from the Ministry of Education, the central government's support for the development of local colleges and universities, the Beijing teaching reform project, and school-level key education reforms project. This achievement optimizes the positioning and goals of talent training, and is guided by the comprehensive reform of three-wide education, improving the curriculum teaching and practical innovation system, and practicing the "three integrations" of the talent training process (integration of art and industry, integration of production and education, integration of paper, media, digital media) Philosophy, pay attention to result-oriented and continuous improvement, and innovate the "studentcentered" printing and packaging compound application talent training model[5].

The main teaching problems to be solved are: (1) Deepen the curriculum ideological and political education under the three-wide education pattern, enhance students' respects and love for Chinese printing civilization and red printing culture, expand their frontier knowledge of the industry, broaden students' horizons, and internalize them into selfconfidence and innovation Power. Solve the problems of incomplete understanding and lack of confidence in the future development of the industry and profession by printing and packaging students; (2) Adhere to the concept of green development, so that the training of professional talents is in harmony with the needs of the industry and Beijing's social talents. Provide technical and talented solutions for the green transformation and upgrading of the printing and packaging industry for the coordinated development of Beijing-Tianjin-Hebei and serving the construction of core functions in the capital. Solve the problem of poor matching of talent training with regional economic development and social needs; (3) Strengthen the cooperation and exchanges between printing and packaging and publishing, art and digital media, and promote the integration of school-enterprise production and education.
Cultivate students' sense of innovation and practical ability, so that they can continuously develop their compound and application-oriented comprehensive qualities. Solve the problems of inadequate cooperation between majors and between schools and enterprises, and the low comprehensive quality of students' practical and innovative ability[6].

\section{AN EFFECTIVE WAY TO CONSTRUCT A TRAINING MODEL FOR PRINTING AND PACKAGING COMPOUND APPLICATION-ORIENTED TALENTS}

Through the following measures, a new printing and packaging innovative talent training model that integrates knowledge transfer, ability training, and quality improvement has been established.

\subsection{Relying on the Dual Innovation Practiced Education System and Internal and External Cooperation Platforms to Organize Printing Culture and Technology Exchanges to Expand Students' Cognition and Horizons}

Supported by the Printing Civilization Inheritance Experience Center of the University Student Double Creation Park, OUT\&IN Printing Workshop and the International Education Institute, through the printing museum and well-known printing companies' visits and inspections, the history of printing literature study, "Everyone tells the story of red printing" , Toppan printing experience activities, design and production of characteristic cultural and creative works, etc, the school carries out activities such as printing cultural exchanges and technology sharing for printing and packaging students. Use the above methods to enhance students' understanding and cognition of my country's splendid printing civilization and the development and dissemination of printing technology, strengthen the entrance professional education of "patriotism, love of school, love of majors" and self-confidence education of red printing culture, and promote curriculum education, practical education people and culture educating people.

\subsection{Based on the Construction of First-class Majors, and Guided by the Transformation and Upgrading of New Engineering Disciplines, Strengthen Education and Teaching Reforms, and continuously Improve the Fit of Talent Training}

The school firmly grasps the general task of first-class professional construction, establishes new engineering reform and upgrade standards, deepens the understanding 
of green printing and packaging strategic theories and planning through professional learning exchanges, academic lectures, and innovation plans, and carries out green scientific research and practical actions ; The school takes students as the center, optimizes and adjusts the school positioning and talent training goals, improves the curriculum teaching system, highlights the green and intelligent development positioning of printing and packaging, and strengthens the pilot role of Bisheng's outstanding and characteristic classes. The school enhances the new requirements of knowledge, ability and quality, and enhances the fit and reputation of talent training and the construction of the capital's core functions, the coordinated development of Beijing-Tianjin-Hebei, and the Made in China 2025[7].

\subsection{Focus on the "Three Integrations", Deepen Inter-professional Exchanges, Technological Integration and School- enterprise Cooperation, and Enhance Students' Innovative Awareness and Engineering Practice Capabilities}

Taking the "three integrations" as the starting point for work, based on printing and packaging media science and technology disciplines, relying on the national green printing and packaging industry collaborative innovation base, printing and packaging materials and technology key laboratory, printing engineering comprehensive training center, and printing electronics engineering technology center, Printing and Packaging Comprehensive Innovation Practice Base and other municipal scientific research and practical innovation platforms and other school-enterprise cooperation platforms to carry out innovative research and application exploration of printed electronics, 3D printing, flexible manufacturing, biological printing and digital interactive media; Based on China's "Internet+" College Student Innovation and Entrepreneurship Competition, Beijing Cultural and Creative Competition, "Challenge Cup" Science and Technology Competition, College Student Innovation and Entrepreneurship Training Program, "Creative Printing" discipline competition and other secondary classrooms and innovative practice activities, the school strengthens the integration of cross-professional arts and crafts and the integration of engineering and literature to cultivate students' comprehensive professional literacy; The school has set up practical training courses for the integration of paper, media, digital media, and graduation internship, graduation design, etc. The school cooperates with scientific research institutions in Beijing and universities (such as the Chinese Academy of Sciences, Beijing Jiaotong University, etc.) to carry out "practical training programs" cooperation projects based on graduation projects, college students' innovation and entrepreneurship plans. School-enterprise linkage, industry-education integration, and promotion of the construction of industrial colleges have greatly enriched students' experience and vision, and promoted the improvement of students' awareness of scientific and technological innovation and engineering practice capabilities[8].

\section{THE INNOVATION OF THE PROJECT}

The innovation of this achievement is reflected in the concept and model of talent training, innovative education system and resource sharing.

The "Red, Green, and Blue Education Project" fits the theoretical basis of the printing and packaging field, making printing and packaging students feel more natural and easier to implement. It helps to enhance students' selfconfidence and pride in the development of the printing and packaging industry and professional learning. The talent training model implied by red, green and blue conforms to our current efforts. The first is to explore the education elements of red printing, the second is to integrate the green and intelligent development pattern of printing and packaging and the whole process of education, and the third is to cultivate professional talents who are looking forward to the future, dare to open up the blue ocean, and have the ability to innovate; The focused and phased implementation of the "red, green, and blue" education project, which is a combination of the "Red Thought Leading Plan", "Green Technology Awareness Plan", and "Blue Innovation Promotion Plan", is not only in line with the phased key goals of the talent training system and the path of realization ,also highlights the orderliness and logic of work development.

"The integration of art and industry, the integration of production and education, the integration of paper, media and digital media" interprets the overall picture of the development of printing and packaging professional education. "Three fusions" are organically combined with the essential education requirements and relevant key elements of our school's printing and packaging specialty disciplines. This is consistent with the school's schoolrunning characteristics and the overall goal of talent training. The construction of a "three-integration" professional internal and external resource collaborative education system is in line with the current connotation and external requirements of the current new engineering construction. The "Three Integrations" achieves the deep integration of paper, media and digital media technology through the integration of cross-professional arts and crafts in the school and the all-round integration of schoolenterprise production and education. It not only finds a clear implementation path for the green transformation and upgrading of the school's printing and packaging major, but also increases student input confidence and enthusiasm for professional learning. The "three fusion" aims to educate people for the party and the country, and cultivate newcomers in the era of composite application publishing and media. 


\section{APPLICATION AND DEMONSTRATION EFFECT OF RESUITS}

\subsection{Enhance Students' Recognition of Printing Culture and Industry, and significantly Improving the Students' Engineering Practice Innovation Ability, Professional Vision and Comprehensive Quality}

In recent years, through a series of activities such as dean's report, professional introduction, seniors and elder sisters in North India, industry development and career planning, and "Red Printing Story Telling Everyone" and other series of activities, students' pride in the printing culture and the professionalism of printing and packaging have been enhanced. The sense of identity, the sense of honor of "love the country, love the school, love the profession" is deeply rooted in the hearts of young students. Combining teaching links such as special professional courses, enterprise special training and summer social practice, the project carried out a journey of exploring printing culture in cooperation between teachers and students, enabling teachers and students to understand the origin and development of printing, and shoulder the mission and responsibility of inheriting printing civilization[9] .The printing and packaging major also cooperates closely with the China Printing Museum, the Chinese Academy of Sciences, Yangzhou Guangling Ancient Book Engraving Society and other units to carry out technical cooperation in the fields of digital reproduction of printed exhibits and the research and protection of China's printed cultural heritage to enhance the cultural attributes of printing.

In the past three years, the 16-level Bisheng Excellent Class, the 16th Packaging Class 1 and its Youth League Branch, and the 18th Bisheng Excellent Class have won the "Beijing Excellent Class Group", "Beijing Pioneer Cup Excellent League Branch", and Beijing Higher Education "Advanced Grassroots Organization" and other honorary titles. Students have won more than 100 prizes in provincial and ministerial competitions held in the past three years. Competitions include the "Challenge Cup" Capital University Students' Extracurricular Academic Technology Work Competition, the National University Digital Art Design Competition, China "Internet +" University Student Innovation and Entrepreneurship Competition Beijing Division, and the "Today's Printing Union Cup" National University Student Printing Technology Innovation Competition. The students also published nearly 30 high-level papers. Students go to study exchanges in overseas universities such as Linköping University in Sweden, University of Leeds in the UK, and through the on-campus all-English foreign teaching courses, bilingual courses and professional training courses, etc., the students' practical innovation ability, international vision and comprehensive quality have been greatly improved[10].

\subsection{Further Promoted the Integration of Professional Resources and Practical Innovation Links, and Achieved Remarkable Results in Education}

Our school has successively won the "Undergraduate Teaching Reform and Innovation Project" of Beijing Higher Education in 2019 and 2020, and has cooperated with the School of Design and Art, the School of Mechanical and Electrical Engineering, and the School of New Media to guide students' graduation designs and innovative works in digital media interaction design, smart packaging, etc. Our school has also carried out in-depth school-enterprise cooperation with Shenzhen Yutong, Shantou Dongfeng, Xiamen Jihong and other more than 10 enterprises in technology development, training courses, student internships and employment, and the effect is obvious. After three years of construction, the printing engineering virtual simulation practiced teaching platform and resources have been basically completed and used for online practical teaching during the epidemic period. It has opened up for the printing process internships of the School of Information Engineering and the School of Mechanical and Electrical Engineering of our school, with good results. The "Virtual Simulation Experiment of Lithographic Offset Printing Process" was recommended to the Ministry of Education to participate in the national first-class virtual simulation experiment teaching course, which better demonstrated the school's successful experience in the construction of a first-class specialty in printing engineering to experts and similar schools. The school also took the lead in the compilation of guidelines for virtual simulation experiment teaching construction projects in six domestic universities of the same kind, including Xi'an University of Technology, Tianjin University of Science and Technology, and Qilu University of Technology, which strengthened the inter-school exchanges and exemplary nature of the project.

\section{CONCLUSION}

Standing at the historical moment when my country's printing and packaging industry is still showing a good momentum of development since the "13th Five-Year Plan", relying on the background of the "Excellent Engineer Education and Training Program" of the Ministry of Education, the printing major of our school has implemented the "Red, Green and Blue" education project to innovate application-oriented talent training model. "Red, green and blue" represents the three primary colors of shade and is one of the printer's labels. The article introduces the background of the project, the main research content of the project, and the training mode of printing and packaging applied talents. The project implements the "Red, Green and Blue" education projects in a focused and phased manner, including the "Red Ideas Leading Plan", "Green Technology Awareness Plan", and "Blue Innovation Promotion Plan". From freshman to senior year, 
innovatively constructed a full-time-line talent training model, which not only combines the phased key goals and realization paths in the talent training system, but also highlights the orderliness and logic of work development. The "Red, Green, and Blue" education engineering teaching results have achieved significant application effects in Beijing Institute of Graphic Communication, and have a good promotion and demonstration effect in the Beijing-Tianjin-Hebei region and similar universities in the industry.

\section{REFERENCES}

[1] X. K. Liu, Open up a New Situation of High-quality Printing Development in China [J], Print Magazine, 2018(10):1-5.

[2]"Development Plan for Printing Industry in the 13th Five-Year Plan Period" [J], Printed in China, 2017(05):10-15.

[3] S. H. He, J. T. Wu, X. Y. Xu, Q. Chen, M. Xu, Analysis of the status quo and demand of printing and packaging talents under the background of artificial intelligence [J], Printing manager, 2020(06):54-59.

[4] J. Lin, The Whole Cooperation Process Between Universities and Enterprises on Training Outstanding Engineers [J], Higher Engineering Education Research, 2012(03):7-23.
[5] J. Lin, Reformation of Outstanding Engineers' Training-Oriented Curriculum System and Course Content [J], Higher Engineering Education Research, 2011(05):1-9.

[6] J. Lin, The Development of General Standards for "A Plan for Educating and Training Outstanding Engineers", [J], Higher Engineering Education Research, 2010(04):21-29.

[7] C. L. Zhang, P. Fang, The Reform and Innovation of Talents Cultivation for Printing and Packaging: Persisting in the Cooperation between School and Enterprise and Carrying out International Communications [J], Journal of Packaging, 2011, 3(03):90-93.

[8] A. F. Zhang, X. F. Liu, Reflection on the Implementation of A plan for Educating and Training Out-standing Engineers" [J], Higher Engineering Education Research, 2010(04):56-59.

[9] G. D. Lv, T. Y. Li, Reflections of the Paths of Constructing and Developing Emerging Engineering Education [J], Higher Engineering Education Research, 2017(03):20-26.

[10] Z. J. Wu, C. L. Huang, The Concept and Cultivation of Applied Talents[J], Higher Engineering Education Research, 2014(02):66-70. 